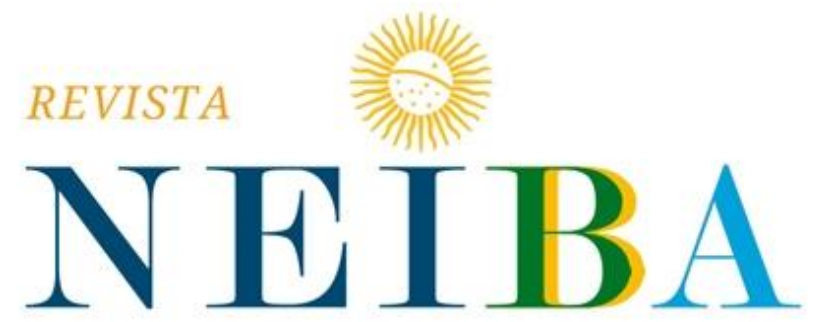

CADERNOS ARGENTINA-BRASIL
Volume 10, 2021, p. 01-22

DOI: 10.12957/neiba.2021.59464 I e59464 IISSN: 2317-3459

\title{
A COBRA E O SAPO DO RACISMO NO BRASIL
}

\section{THE EVOLVING NATURE OF RACISM AND ANTI-RACISM IN BRAZIL}

\section{J. A. Lindgren-Alves ${ }^{1}$}

${ }^{1}$ Embaixador de carreira, aposentado, nascido em Niterói, RJ, em 1946, bacharel em Direito pela UFF, com curso de Altos Estudos de Relações Internacionais do Instituto RioBranco (Brasília, 1998). Membro atual do Comitê Assessor do Conselho de Direitos Humanos das Nações Unidas (Genebra, 2019-2021), ex-membro do Comitê para a Eliminação da Discriminação Racial - CERD (Genebra, 2002-2018). Foi o primeiro diretorgeral do Departamento dos Direitos Humanos e Temas Sociais do Itamaraty (Brasília, 1995-96), membro da antiga Subcomissão de Prevenção da Discriminação e Proteção de Minorias, da ONU (Genebra, 1994-96) e delegado às Conferências Mundiais sobre Direitos Humanos (Viena, 1993), População e Desenvolvimento (Cairo, 1994), Desenvolvimento Social (Copenhague, 1995), Situação e Direitos da Mulher (Pequim, 1995), Assentamentos Humanos (Istambul, 1995) e Racismo, Discriminação Racial e Intolerância Correlata (Durban, 2001). Depois de aposentado foi Secretário Executivo do Instituto de Políticas Públicas de Direitos Humanos, do Mercosul (Buenos Aires, 2018). Brasília, Brasil. E-mail: lindgren.alves@hotmail.com ORCID: https://orcid.org/0000-00016258-6201

Recebido em: 20/04/2021. 
RESUMO

A morte repulsiva de George Floyd nos Estados Unidos trouxe de volta a luta contra o racismo estrutural para a frente dos movimentos sociais no mundo. O presente ensaio sumaria tendências gerais da evolução da questão racial no Brasil, para chegar à situação atual. Nesta, a militância antirracista se torna crescentemente radical, enquanto a destruição de conquistas prévias pelo governo extremista de direita prossegue sem oposição efetiva.

Palavras-chaves: Racismo Estrutural; Antirracismo; Brasil.

\section{ABSTRACT}

The outrageous killing of George Floyd in the United States brought back the fight against structural racism to the forefront of social movements in the world. This essay sumarizes general trends of the evolution of the racial question in Brazil, in order to reach the current Brazilian situation, in which advocacy of antirracism turns increasingly radical, while destruction of former advances goes on by the extremist far right government in power, without concrete opposition.

Keywords: Structural Racism; Anti-Racism; Brazil. 
Assim como a cobra muda de pele, o racismo brasileiro também sofre mutações. Não chega a transformar-se em borboleta, como ocorre com as lagartas. Nem tampouco, quando é larva, evolui para leve mariposa. Importante é impedir que a metamorfose não seja para mariposa bruxa (com devido respeito por todas as feiticeiras), ou cascavel venenosa de chocalho novo.

No cenário tenebroso da pandemia do Covid-19, poucos acontecimentos dela desvinculados conseguiram chamar atenção a ponto de deixarem as estatísticas de mortes e contágios em segundo plano. Foi o caso do assassinato por asfixia do cidadão norte-americano negro George Floyd em Minneapolis, em 25 de maio de 2020, por policial branco ajoelhado sobre seu pescoço durante mais de oito minutos. A execução covarde, insensível aos apelos sufocados da vítima, diante de outros agentes impassíveis, foi gravada e logo divulgada. Sua brutalidade gerou uma comoção que sacudiu o planeta, exigindo o fim do racismo. Nos Estados Unidos, as demonstrações de afro-americanos revoltados, a que se associavam brancos solidários, e as reações do Presidente Donald Trump multiplicaram-se com violência até a segunda quinzena de julho. Algumas culminaram em cenas de batalha entre tropas federais uniformizadas e desafiantes civis à paisana, propiciando imagens semelhantes às de uma guerra civil.

No Brasil, onde a violência policial acarreta mais mortes, inclusive de crianças negras, também houve manifestações de rua. Duraram pouco, quase sem atos de vandalismo. Tal comedimento surpreende, num período em que o racismo nas redes sociais assume feições agressivas, a pregação da consciência negra é intensa, e a maioria da população se declara negra ou parda.

O momento é oportuno para insistir, de meu lugar de fala, privilegiado, em certas posições nem sempre bem entendidas. Tendo sido a primeira pessoa que propôs na ONU, em 1994, a ideia da Conferência de Durban de 2001², acredito que não precise explicitar meu antirracismo. Registro apenas, em suporte referencial ao que direi neste texto, que o tenho praticado por mais de trinta e cinco anos, como delegado e como perito, em

\footnotetext{
2 V. descrições analíticas desse episódio em meus livros “Os Direitos Humanos na Pós-Modernidade”, São Paulo, Perspectiva, 2005, pp 115-121, e "A Década das Conferências (1990-1999)", Posfácio à 2a Edição, Brasília, FUNAG, 2018, pp 512-514. Outro testemunho consultável é da militante Edna Roland ("Depoimento", Rio de Janeiro, CPDOC/FGV, 2004, pp.83-4), que foi Relatora Geral da Conferência.
} 
diversos órgãos internacionais. É com base nessa experiência que avalio, por exemplo, a riqueza dos estudos brasileiros recentes sobre o tema, entre os quais os de Silvio Almeida e Djamila Ribeiro. Meu entusiasmo arrefece, porém, ante iniciativas revoltantes do governo, engolidas como o sapo seduzido pela cobra.

\section{RACISMO ESTRUTURAL E LUGAR DE FALA: O REFINAMENTO TEÓRICO DA CONSCIÊNCIA NEGRA}

Se, por um lado, é fato que a pós-modernidade se afirmou contra as metanarrativas do progresso, do colonialismo civilizador, do lluminismo, do marxismo como caminho para a emancipação universal, é fato também que todos os discursos racionalistas da modernidade, rejeitados como eurocêntricos depois do desmanche do chamado "socialismo real", vinham sendo corrigidos desde muito antes. Malgrado as reservas de personalidades que, por desconhecimento de parte de sua obra, ainda veem Marx como o europeu tipicamente racista do século XIX, seus instrumentos de análise já vinham sendo reinterpretados por intelectuais caribenhos como C.R.L. James e Eric Williams, o afro-americano W.E.B Du Bois e o martiniquense Aimé Césaire. Equiparando a ideia de classe social à de raça, foram eles pioneiros da corrente que ampliou a visão marxiana do sistema escravista como "vestígio de um modo arcaico de produção, eventualmente relacionado à acumulação primitiva do capitalismo", acentuando, ao contrário, o papel do racismo como base ideológica da expansão capitalista da Europa. Foi o efeito da divisão de seres humanos em categorias diferentes, como "civilizados" e "selvagens", que teria permitido a constituição sistêmica do escravagismo, do colonialismo e da dominação dos "brancos" sobre os povos conquistados. Tornou-se, assim, o trabalho escravo dimensão essencial do capitalismo. É nessa linha de explicação abrangente que, superando a transposição mimética dos modelos de antirracismo norte-americanos, vejo enquadrar-se a interpretação do racismo estrutural pelo professor Silvio Almeida.

Construído sobre diversos aportes estrangeiros e brasileiros, entre os quais os de Roger Bastide, Florestan Fernandes, Guerreiro Ramos, Fernando Henrique Cardoso e Octavio lanni, esse enfoque socioeconômico, distante do tradicionalismo patriarcal de Gilberto Freyre, se apresenta oposto ao velho mito acomodatício de uma democracia racial brasileira. A interpretação das três raças miscigenadas em forçada harmonia, 
extraída de Casa Grande \& Senzala, foi cultivada, como se sabe, pelo Estado Novo e pelo regime militar, e agora se insinua de novo na doutrina oficial brasileira.

A análise do racismo estrutural por Silvio Almeida não enfoca apenas a realidade brasileira, mas a formação e expansão de todo o sistema ocidental, usando os instrumentos marxianos, acrescidos de outras interpretações filosófico-políticas do mundo contemporâneo. Dentre elas se destacam as noções, hoje incontornáveis, de necropoder e necropolítica, do filósofo camaronense Achille Mbembe, as quais, passando sobre a biopolítica dos corpos, de Michel Foucault, desvelam o estado de exceção permanente, com suspensão de direitos, exposto por Giorgio Agamben, e revelam a política de administração da morte. Conquanto praticada já anteriormente pelo sistema capitalista, a ideia da necropolítica adquire particular atualidade no contexto da pandemia do coronavírus. Basta ver, nesse sentido, as estatísticas desagregadas de óbitos nos Estados Unidos e no Brasil, maciçamente concentrados na população negra e pobre, em contraste com o número total de contaminados.

Na teorização de Silvio Almeida, o racismo, mais do que um epifenômeno do modo de produção, seria elaboração cultural inversa, formadora do processo de construção material e funcionamento das sociedades "modernas". Envolve e extrapola aquilo que entre os peritos do CERD é dado como definição suficiente do racismo estrutural: fenômeno pelo qual a falta de provisão de meios de subsistência aos ex escravos, quando da abolição da escravatura, deixou-os entregues a si mesmos em condições inviáveis, é estendida a seus descendentes, em situação de exclusão permanente. Para Silvio Almeida, o racismo, antecedendo a colonização de outros continentes pela Europa, seria a hierarquização essencial do humano que "naturalizava" o elemento europeu como civilizado, superior e dominador, e o elemento "negro" ou nativo como selvagem, inferior, subalterno, transformando-o em meio de produção apropriável como qualquer animal. Continuado, depois de legalmente extinto o escravismo, nas condições socioeconômicas da cultura branca, transmitida pela família e pela educação numa discriminação inquestionada, o racismo seria fator estruturante: permeia de desigualdade racial toda a sociedade, mantendo os "negros" numa marginalidade que atende à classe dominante, permitindo-Ihe desconsiderar as necessidades dessa 
"minoria". Do racismo estrutural todos os integrantes da sociedade participam, inclusive as vítimas, que o assimilam e disseminam inconscientemente. À desigualdade que o racismo estrutural provoca não bastam ações afirmativas, certamente úteis para a integração de pessoas discriminadas na sociedade de classes. Para sua erradicação, porém, seriam necessárias reformas profundas, capazes de corrigir as desigualdades que o capitalismo acarreta. Racismo estrutural e racismo institucional não se confundem com o racismo individual, ocultado ou assumido, facilmente identificado ${ }^{3 .}$

Vinculada ao conceito de racismo estrutural situa-se a noção de lugar de fala, erroneamente interpretada como forma de censura que, por definição, excluiria os brancos do discurso antirracista. Tendo como intérprete Djamila Ribeiro, personalidade destacada do feminismo negro brasileiro, Lugar de Fala, conforme explicitado em seu livro homônimo, é a consciência da bagagem de discriminações e preconceitos sofridos, de um lado, ou de prerrogativas herdadas e exercidas, de outro, na determinação da posição da pessoa na sociedade. A experiência da mulher negra é diferente da experiência da mulher branca, o que justifica as postulações sociais específicas do feminismo negro. Se os brancos são o "normal", o "universal", o negro é a alteridade estigmatizada, a mulher negra constitui o Outro dentro do Outro, várias vezes

\footnotetext{
${ }^{3}$ Faço essa tentativa de resumo a partir do livro Racismo Estrutural e de vídeos com Silvio Almeida disponíveis no Youtube. E abro aqui um parêntesis para assinalar uma observação minha, essencial para o entendimento correto do conceito de racismo estrutural. Na linguagem da Península Ibérica, até hoje, "negros" é designação despicienda para todos os não brancos no país, imigrantes e cidadãos nacionais. Essa "colorização" como sinalização verbal de uma diferença muitas vezes não visível é comum em toda a região do Mediterrâneo, inclusive no Magreb, por parte dos cidadãos autoconsiderados brancos, epidermicamente amorenados. Algo semelhante ocorre na parte setentrional do continente e dos países da Europa na maneira de referir-se aos sulistas nacionais e estrangeiros, geralmente mais pobres e vistos como "primitivos". No Brasil, "negros" para a classe média eram - e estão voltando a ser - todos os pobres, aí inclusos os pobres brancos e mestiços, que também têm preconceitos contra os pretos. Generaliza-se, portanto, em todos esses casos, uma "racialização" social imposta, uma diferenciação que se pretende naturalizar como escusa para a marginalização de grupos etnicamente "diferentes". Embora presente, por muitos séculos, entre os árabes que escravizavam negros africanos muito antes da chegada de portugueses ao continente subsaariano, o "racismo" estruturante baseado em cor somente ganhou ares programáticos na colonização da América, no Século XVI, vindo a tornar-se "científico" na virada dos séculos XVIII para XIX. Dentro da própria Europa, o sentimento racista dominante era mais "religioso" ou classista, embora os negros sempre fossem também inferiorizados. Durante o período colonial da Irlanda, como parte do Reino Unido, os irlandeses, católicos, eram considerados "raça subalterna" para os dominadores ingleses, protestantes anglicanos. Quando emigraram para os Estados Unidos, os irlandeses foram igualmente vítimas de discriminações, superadas somente quando reconhecidos como "brancos" pelos protestantes anglo-saxões. Passaram então, eles próprios, a discriminar os negros, egressos da escravidão. O caso extremo de discriminação étnica na Europa sempre foi o antissemitismo, sendo os judeus segregados, agredidos e perseguidos desde a Idade Média. Hoje, a discriminação europeia é muito mais complexa e abrangente, contra qualquer pessoa ou grupo "diferente", voltando a vincular-se a noções políticas de direita, como o identitarismo nacional "autêntico", o cristianismo tradicional excludente, o helenismo radical dos gregos do partido Aurora Dourada, a russofilia mística dos russos pós-comunismo, o "arianismo" dos neo-nazistas alemães e nórdicos.
} 
discriminada. Daí, por exemplo, a naturalidade com que se encaram as babás, que deixam de cuidar dos próprios filhos para cuidar de filhos alheios, as empregadas domésticas que, na pandemia, correm o risco de contaminação em transportes coletivos para tratar de terceiros, garantindo-Ihes um conforto na quarentena que elas não podem ter nunca. A consciência do respectivo lugar de fala é, portanto, necessária para o "empoderamento" da pessoa marginalizada, e para que o discurso de quem o profere por empatia seja autêntico.

Tal como Silvio Almeida, que postula o antirracismo para todos, negros e brancos, com vistas à superação da "raça", Djamila Ribeiro afirma valorizar, para a luta da mulher negra, o papel dos brancos e brancas conscientes de seus privilégios. Sílvio insiste na necessidade de o antirracismo se estender à economia, lembrando que cada aumento de imposto indireto incide mais sobre os pobres, logo os "negros" em sentido lato, do que sobre os "brancos", detentores de melhores condições. E quem mais paga entre todos é a mulher negra, discriminada até entre os discriminados e primeira a perder seu emprego.

Ambos autores têm reações compreensíveis de autodefesa diante das posturas esquerdistas tradicionais, que criticam o divisionismo de suas preocupações prioritárias, como fator de enfraquecimento de lutas abrangentes. Tais críticas não levam em conta o nível aguçado de conscientização que essa focalização propicia, sem necessariamente enfraquecer sua determinação para a superação geral de iniquidades. Desde que o foco prioritário na "raça" ou na etnia, assim como no gênero, não se transforme em exclusivismo, com interpretações reducionistas do real. Nem leve a rejeição de discordâncias tópicas ao ponto de desconsiderar a cooperação de aliados.

\section{CONQUISTAS LIBERAIS E DISTORÇÕES CORRENTES}

Enquanto Silvio e Djamila aparecem como mentores destacados do ativismo negro de esquerda, cujos objetivos finais somente podem ser alcançados por transformações revolucionárias, os avanços dos segmentos preto e pardo da população brasileira têm sido obtidos por iniciativas liberais. Estas se destinam a promover sua melhor integração 
na sociedade de classes, conforme estudada há décadas por Florestan Fernandes ${ }^{4}$. Não quero com isso dizer que Florestan fosse apenas um pragmático de centro ou de direita, nem creio que os avanços reformistas sejam menosprezados por Silvio e Djamila. Chamo os avanços de "liberais" porque se inspiram em propostas dos chamados "liberais" dos Estados Unidos, embora sejam intrinsecamente iniciativas social-democratas.

Ações afirmativas por cotas, copiadas ou não do modelo norte-americano, nada têm de esquerdistas. Enquadram-se nas "medidas especiais" contempladas na Convenção Internacional sobre a Eliminação da Discriminação Racial, adotada pela ONU em 1965, por influência do Movimento pelos Direitos Civis nos Estados Unidos dos anos de John Kennedy e Lyndon Johnson. Respondem mais ao "sonho" de Martin Luther King por uma meritocracia indiferente da cor da pele, do que ao radicalismo dos Black Panthers. Graças à conscientização e à pressão dos negros brasileiros, o Brasil posterior ao regime militar passou a contar com números crescentes de pretos e pardos na academia e na política, assim como em profissões liberais, no funcionalismo público, na magistratura, na diplomacia, nos meios de comunicação e em tipos de empreendedorismo variados. Cresceu também, inesperadamente, junto com a emergência de uma classe média negra expressiva, um fato novo na sociedade brasileira: o número de protestantes pretos e pardos, inclusive pastores, nas denominações neopentecostais. Os crentes afrodescendentes, que em 2020, segundo os dados disponíveis, corresponderiam a $59 \%$ do total de evangélicos no país ${ }^{5}$, já ultrapassavam de longe o número de praticantes de religiões de matriz africana. Estas são repudiadas agora não mais pela Igreja Católica, mas pelos fundamentalistas protestantes, que as veem como paganismo.

Se, como registrou Florestan Fernandes nas décadas de 1950-60, o catolicismo no Brasil pós-abolição produziu entre os brancos um "preconceito de ter preconceito", eticamente compensatório das relações iníquas herdadas do escravismo, no cenário contemporâneo, dominado pela cultura norte-americana, essa formulação soa anacrônica.

\footnotetext{
${ }^{4}$ Seu livro mais marcante se intitula exatamente $A$ Integração do negro na sociedade de classes, impresso pela primeira vez na Tipografia da Faculdade de Filosofia, Ciências e Letras da Universidade de São Paulo, em 1964. Os estudos na mesma linha prosseguiram depois em outras obras.

${ }^{5}$ https://www.brasil247.com/brasil/datafolha-mulheres-e-negros-sao-maioria-entre-evangelicos-brasileiros
} 


\section{O “PRECONCEITO DE TER PRECONCEITO” EM 2020}

Resultante de comparação com a situação racial radicalmente segregada dos Estados Unidos, a ideia de um preconceito anti preconceito, por mais sagaz que fosse para sintetizar a idiossincrasia racial brasileira, não deixava de carregar, ela própria, uma dose de preconceito. Primeiro, por dar a entender que os brancos, em função de um determinismo histórico sui generis, teriam impossibilidade inerente de favorecer a integração. Segundo, por não levar em consideração o avanço ideológico representado por tal "preconceito de ter preconceito" num país cujos governantes, até pouco tempo antes, haviam incorporado o "racismo científico" da Europa, com políticas de imigração dirigida para fins branqueadores da população nacional. O simples fato de o brasileiro branco médio ter passado a declarar-se herdeiro miscigenado das três raças formadoras foi um passo gigantesco, hoje esquecido, auxiliado pelo trabalho de Gilberto Freyre, inovador na década de 30. Que o autor de Casa Grande \& Senzala tenha depois explorado o êxito dessa obra com objetivos questionáveis não invalida o pioneirismo de sua abertura analítica, diferente do "indianismo" dos modernistas europeizados de 1922. Ela, por sinal, não falava em "democracia racial", nem omitia descrições de abusos sistêmicos e torturas.

A assunção de uma postura anti preconceito pelos brasileiros não queria dizer que as pessoas encarassem o Brasil como um país isento de iniquidades. Florestan sabia disso. O aspecto dissimulador de discriminações não era necessariamente percebido pelo cidadão comum, como, aliás, pode não o ser ainda hoje, num contexto de racismo institucional. O que não havia, com certeza, era uma consciência social abrangente, capaz de descrever e combater o racismo estrutural, que vai muito além do preconceito individual. Tampouco havia, por outro lado, uma cultura de ódio racial semelhante à que sempre houve nos Estados Unidos.

A rejeição ao mito da democracia racial brasileira vem já de longa data. Sua interpretação como modelo de convivência harmônica que ocultava a discriminação sob disfarce de falsa tolerância vinha sendo adotada por ativistas negros e brancos desde antes do Estado Novo, retomada com mais força depois. O pavor de ver o Brasil 
equiparado ao violento sistema segregacionista norte-americano, que inspirou a divulgação do mito no Brasil e no exterior, pode, aliás, ter sido influente também, contrario sensu, na modificação de posturas da classe dominante e da classe média brasileira, durante o regime militar. Foi nesse período arbitrário, de 1964 a 1985, negacionista do racismo no país, que a elite intelectual de oposição redescobriu e divulgou a figura de Zumbi como herói da liberdade, valorizou a macumba, o candomblé, a capoeira, a cultura negra da Bahia, abraçou as roupas de inspiração africana, adotou cabelos Black Power, retomou a busca das raízes nacionais nordestinas ${ }^{6}$. Tendo apoiado o Teatro Experimental do Negros e o Movimento Negro Unificado, foi ela, envolvendo brancos e negros, quem mais denunciou o sistema interracial vigente, que nada fazia para superar a pobreza estratificada dos pretos, mulatos e caboclos ${ }^{7}$. Evidentemente tudo isso, que ocorria fora do governo, ganhou força com a redemocratização, consolidada juridicamente na Constituição de 1988.

Desde os anos 1990 até 2016, muitas iniciativas federais e estaduais foram tomadas com vistas à melhora da situação dos negros na sociedade brasileira. A Fundação Cultural Palmares, criada em 1988 junto ao Ministério da Cultura e com estatutos definidos em 1992, terá sido das primeiras instituições governamentais que se propunha promover a cultura negra, com vistas à elevação da autoestima. A ela se seguiram outras, como o estabelecimento da SEPPIR (Secretaria de Políticas de Promoção da Igualdade Racial) em 2003. "Palmares", designação de fato histórico celebrado e de fundação promotora cultural dos negros do Brasil, permanecia consagrada como um ícone, até recentemente.

Embora muitas ações importantes já estivessem em curso nos três níveis da federação, o ponto de inflexão na asserção do movimento negro como elemento aglutinador, capaz de influenciar toda a sociedade, parece ter sido a preparação e participação de várias de suas lideranças na Conferência Mundial de Durban, de 2001. Em parte graças à receptividade do Itamaraty às postulações da sociedade civil e, em

\footnotetext{
${ }^{6}$ É de Martinho da Vila o memorável samba-enredo que dizia: "Aprendeu-se a liberdade combatendo em Guararapes (...) Brasileiros irmanados sem senhor e sem senzala, e a Senhora dos Prazeres transformando pedra em bala". ${ }^{7}$ No período atual, parece feio recordar a importância cultural e política do show Opinião, com o nordestino retirante preto João do Vale, autor da emblemática "Carcará", cantada por Nara Leão e depois Maria Betânia, ressaltando em outra música: "O problema não é bem eu, é Mané, Pedro e Romão (...) continua(m) no sertão. Não puderam estudar, nem sabe(m) fazer baião".
} 
especial, do movimento negro, com o Departamento de Direitos Humanos e Temas Sociais estabelecido em 1995, ao trabalho do Embaixador Gilberto Saboia, então Secretário Nacional dos Direitos Humanos e sempre aliado à causa da igualdade, e da Relatora Geral da conferência, a ativista Edna Roland, com longa experiência no tema, a interação das lideranças negras nacionais com a delegação governamental foi permanente durante todo o evento. Em função disso, logo que a delegação oficial dos Estados Unidos se retirou da Conferência (em apoio a Israel), representantes do movimento norte-americano foram dizer à delegação brasileira que os African-Americans passavam a considerar-se representados pelo Brasil. Malgrado os atentados terroristas do Onze de Setembro, três dias depois do fim do evento, que quase fizeram o mundo esquecer essa importante conferência, os integrantes do movimento negro brasileiro, além de regressarem à pátria satisfeitos, passaram a contar com a Declaração e o Programa de Ação de Durban como referência para o que iriam propor.

Embora se considere que o modelo de atuação para todos os países tenha sempre sido norte-americano, para analistas dos Estados Unidos nos anos 90, o conjunto de medidas aplicadas naquele país teria produzido uma "brasilianização da América" ${ }^{8}$. 0 racismo norte-americano teria deixado de ser ostensivo, mantendo-se sub-reptício nas discriminações de natureza social. Se assim fosse realmente, o "preconceito de ter preconceito" brasileiro, percebido por Florestan Fernandes, teria perdido sua lógica católica, superadora do sentimento de culpa pela desigualdade racial anticristã. De minha parte, achava eu, então residindo na Califórnia, que essa interpretação decorria de otimismo exagerado dos liberais. O que os jornais estampavam diariamente eram atos de violência racista repugnantes, que não se viam no Brasil. Quando vivi na costa oeste dos Estado Unidos, por razões de ofício, de 1996 a 2002, mantive contatos frequentes com diversos setores da sociedade local. Ela continuava espacialmente segregada, ainda que não por vontade oficial, em divisões raciais e subdivisões étnicas, muito mais do que a sociedade brasileira. Até mesmo os negros afluentes tendem a manter-se separados, como se vê na bonita Oakland, grande cidade portuária da Baía de São Francisco, quase

\footnotetext{
8 Entre eles Michael Lind, The Next American Nation, Nova York, Free Press, 1996, p. 14 e 215-16, e Anthony Marx, Making Race and Nation, Cambridge University Press, 1998, p. 273.
} 
exclusivamente negra, inclusive na gestão do porto. Menos miseráveis do que nossas favelas, mas muito mais degradados do que os bairros brancos das metrópoles, os bairros hispânicos, negros, chineses, têm vizinhança etnicamente definida. Nos anos 90, conquanto não mais visível como antes, o ódio racial continuava forte na "América profunda", dos rednecks - "pescoços vermelhos" pelo calor do sol na lavoura, apelido depreciativo dos agricultores brancos do interior -, protestantes e tradicionalistas, muitos dos quais integrantes de associações supremacistas, denominadas "milícias"9. Por outro lado, no sentido inverso, a influência do movimento negro norte-americano no homólogo brasileiro sempre foi marcante, tendo crescido de maneira exponencial com a intensificação do processo de globalização, que é também cultural.

Seja em decorrência do modelo norte-americano, seja pelo temor competitivo dos brancos brasileiros diante da ascensão gradativa dos negros, seja em reação aos excessos de cobranças incorporadas pelas instituições domésticas, a verdade é que o preconceito assumido, no Brasil, não é mais tabu. Apresenta-se sem disfarce na sociedade nacional, que também parece haver implantado o cultivo do ódio interracial, nos dois sentidos. A metamorfose da velha larva racista colorida, que se assume agora vampiresca, completase, no Brasil contemporâneo como nos Estados Unidos, pelo desenvolvimento de hipersensibilidades ativas e reativas.

Enquanto a discriminação institucional tem sido contrabalançada por cotas raciais e étnicas, e o racismo individual, pela abertura formal do sistema judicial para ações indenizatórias, raramente exitosas, o racismo estrutural perdura. O preconceito racial se expande, disseminado e magnificado pela internet, neste período de polarizações assustadoras, enquanto a intolerância contamina a sociedade inteira. Já não são raras as agressões físicas, sem falar dos abusos em operações de repressão ao tráfico de drogas, das perseguições de "milícias" toleradas a assistentes sociais, dos assassinatos políticos, como o da vereadora Marielle Franco, da brutalidade dos extremismos ostentados em manifestações de rua.

\footnotetext{
${ }^{9}$ Como as Milícias de Michigan, de Montana, da Califórnia e outros estados, assemelhadas à Ku-Klux-Klan. Escrevi sobre o assunto o ensaio "No peito e na raça: a americanização do Brasil e a brasilianização da América", publicado na revista Impulso, $n .27$, vol. 12, 2000, edição comemorativa dos 500 anos do Descobrimento, e que veio a compor depois o capítulo 4 de Os Direitos Humanos na Pós-Modernidade.
} 
A esses fenômenos graves agregam-se outros, temíveis para nossas tensas relações interraciais: a "cultura do cancelamento" copiada dos "progressistas" norte-americanos, a ideologia que encara os opositores como agentes de uma "conspiração comunista", o restabelecimento oficial do mito da "democracia racial", o esvaziamento de instituições antirracistas, a deturpação da SEPPIR e da Fundação Palmares. Tudo isso vem ocorrendo com consequências destrutivas para um movimento negro surpreendentemente abúlico, antes mesmo do início da pandemia, em contraste com a radicalização do discurso militante.

\section{PRINCIPISMOS CANHESTROS E CANCELAMENTO}

Enquanto a linguagem expurgada era razoável, a aceitação do "politicamente correto" não causava problema. A multiplicação de cobranças, algumas das quais estapafúrdias, e a expansão infinita de focos, porém, tornaram essa "correção" uma obrigação imposta e irritante, engendrando reações contrárias. A repetição obsessiva de que "o Brasil é um país racista" nos meios de comunicação - que, aliás, fazem o mesmo com os termos "machista", "homofóbico", "transfóbico" e outros barbarismos -, é um exemplo de tolice expletiva e contraproducente, que ajuda mais os reacionários do que as vítimas de discriminação.

No CERD, Comitê para a Eliminação da Discriminação Racial, órgão criado pela Convenção Internacional sobre o assunto, de 1965, uma das conquistas doutrinárias, mantida desde sua constituição em 1970, é o entendimento do racismo como fenômeno planetário. O sentimento discriminador, que nem sempre se externaliza em ações conscientes, é um mal construído culturalmente em todas as sociedades, ainda que não endossado pelo respectivo Direito Positivo. Tal entendimento é reiterado pelo Comitê a todos os Estados que insistem em se declarar isentos de racismo, tal como o Brasil fazia durante o regime militar. Foi, portanto, um gesto simbólico de superação do mito da democracia racial o reconhecimento semioficial, nos anos 90, de que o Brasil seria "um país racista". Embora, desde o fim do apartheid sul-africano, nenhum país o seja pela legislação, no entendimento do órgão internacional competente, o CERD, todos o são na prática. Não faz sentido, portanto, bradar e repetir "Meu país é racista", frase que simplesmente agrega irritação a governos empenhados em reformas sérias. 0 
importante é que os Estados adotem normas e ações destinadas a garantir igualdade real sem segmentos excluídos em razão de "raça, cor, descendência, origem nacional ou étnica", bases da discriminação definidas no Artigo $1^{\circ}$ da Convenção para a Eliminação de Todas as Formas de Discriminação Racial. Esse objetivo universalista, para ser atingido, requer, muitas vezes, conforme a Convenção, medidas especiais para grupos específicos, "nos campos social, econômico, cultural e outros", até que suas condições se equiparem às da maioria (Artigo $2^{\circ}$, parágrafo $2^{\circ}$ ). Exige políticas e ações decisivas (Artigo $5^{\circ}$ ), estas sim, reiteradamente cobradas.

Pelos motivos estruturais acima analisados, o racismo ostensivo ou insidioso impede ou sabota políticas e ações decisivas. Daí a imprescindibilidade de cooperação entre os militantes e simpatizantes do antirracismo. É aí que a questão do "principismo" irrealista preocupa, pois tende a funcionar em sentido contrário ao desejado. Quando a intolerância extremista se impõe sobre o diálogo construtivo, perdem os proponentes e apoiadores da causa comum que deve interessar a todos: o estabelecimento de condições iguais, respeito e aceitação entre as "raças" ou etnias, sem exclusões.

Princípios são coisas boas, valores inspirados na ética. Precisam, para ser praticados, atentar para as circunstâncias. O "principismo" irrealista é censura, não rima com democracia. Afasta militantes não fundamentalistas e hostiliza potenciais aliados. Excessos identitários "da esquerda" têm dado votos à direita. E, por mais que militantes radicais digam o contrário, o maior e mais perigoso inimigo da igualdade, seja ela racial, social ou de gênero, é a extrema direita ultranacionalista. Para ela a identidade como valor é outra, tradicionalista excludente, e a desigualdade de raças e etnias, encarada como "natural", o normal. O espírito dominante da atualidade é retrógrado, antiigualitário, fanaticamente religioso. Chamá-lo de conservador é elogio ingênuo. Desprezar antirracistas que não compartilham alguma posição identitária expletiva "progressista" é atuar contra o importante da causa.

Nos Estados Unidos, a intolerância "liberal" com opiniões dissidentes é antiga. Há décadas que as chamadas culture wars (guerras de culturas) afastam do antirracismo e do feminismo libertário personalidades de atuação positiva. Desconfiado de Barak Obama, exultante com o "progressismo" de Hillary Clinton, o "liberalismo" ajudou a 
eleger Donald Trump em 2016. Como no Brasil o progressismo acrítico, verbalizado sem programa abrangente, ajudou a eleger o falso messias Bolsonaro.

$\mathrm{Na}$ onda de protestos provocados pela morte de George Floyd nos Estados Unidos, o movimento negro adquiriu nova força em todo o mundo. A campanha Black Lives Matter (Vidas Negras Importam) conferiu ao antirracismo renovado um destaque tão eficaz que o próprio Donald Trump, cultivador de supremacistas brancos, teve que fazer concessões. Produziu, também, por outro lado, uma crispação identitária tão aguda que levou acadêmicos, escritores e artistas, de esquerda e direita moderada, entre os quais Noam Chomsky, Francis Fukuyama, Mark Lilla, Margaret Atwood, Salman Rushdie e Wynton Marsalis, a divulgarem carta aberta, publicada em 7 de julho de 2020, de condenação à "cultura do cancelamento". Persecutória a qualquer suspeita de inconformismo ao progressismo, tal "cultura", incorporada temerosamente por diretores de várias instituições, tem sido responsável pelo fenômeno da "lacração": demissão preventiva de pessoas, suspensão de livros e autores, proibição de tópicos jornalísticos e outras formas de repressão à liberdade de expressão. Diz a carta, entre outros pontos:

"As forças antiliberais vêm ganhando vigor em todo o mundo, e têm em Donald Trump um aliado poderoso, que representa ameaça real à democracia. Não se pode, porém, permitir à resistência o endurecimento com um tipo próprio de dogma ou coerção, que os demagogos de direita já vêm explorando. A inclusão democrática que queremos somente pode ser alcançada se falarmos claramente contra o clima de intolerância que se instalou em todos os lados. (...) Essa atmosfera sufocante vai acabar prejudicando a causa mais vital de nosso tempo. A restrição ao debate, seja por um governo repressivo, seja por uma sociedade intolerante, fere invariavelmente aqueles que não dispõem de poder, e torna todas as pessoas menos capazes de participação democrática." 10

Entendo que no Brasil a situação não atinge esse nível, por mais que reações assemelhadas já tenham ocorrido a críticas bem-intencionadas. Como vi e senti em Genebra, em meus dezesseis anos de CERD, e vejo no Brasil agora, uma parte ponderável das energias militantes é gasta contra posturas de outros ativistas. Talvez os mesmos

\footnotetext{
${ }^{10}$ https://harpers.org/a-letter-on-justice-and-open-debate/ (meu grifo e minha tradução).
} 
intelectuais que ora reforçam a consciência negra com um refinamento inédito possam ajudar a reparar esse desperdício. Vale a pena lembrar que o discurso do ódio identitário sempre foi de direita. É ele que encara discordâncias pontuais como oposição essencial. Incorporar tal atitude à esquerda é levar o antirracismo para a direita.

Não é por ignorância que o rótulo "fascismo de esquerda", oxímoro usado pelo Presidente Trump para justificar sua repressão violenta à movimentação deslanchada pela morte de George Floyd, vem sendo repetido com insistência alhures. A lógica é a mesma adotada por pseudointelectuais brasileiros de extrema direita, quando forçadas a condenar o fascismo histórico italiano e o nazismo alemão de Hitler: classificá-los como ideologias "de esquerda".

\section{AVANÇOS E RETROCESSOS NA LUTA CONTRA O RACISMO}

Conforme disse no início, apreendo com admiração e proveito os ensinamentos das novas lideranças negras brasileiras. Eles me abrem mais o horizonte. Tenho, porém, meus temores. Encantam-me os lives com o Silvio Almeida e Djamila Ribeiro, filósofos de altíssimo nível, e outros ativistas coevos, como a urbanista Joice Berth, embora sinta o desnível entre os oradores e a audiência nos programas a que assisto. Noto o contraste entre as análises aprofundadas de assuntos que são realmente complexos e o principismo simplório das perguntas e comentários do público. Observo, em colunas jornalísticas, uma separação abissal entre o discurso agressivo dos autores e o distanciamento cognitivo do cidadão comum. Esse é um dos problemas que esvaziam de sentido prático as forças democráticas para estancar a onda da extrema direita.

Numa fase de polarização espantosa, em que demagogos grosseiros são os que vencem eleições, pergunto-me se tais discursos, negros e brancos, voltados para ouvintes sofisticados, podem ter o resultado desejado. Receio que afastem o homem e a mulher não preparados. Estes se identificam logo com políticos toscos de linguajar simplório, que detestam intelectuais e prometem esmagar os "comunistas". Preocupa-me o contraste chocante entre a sofisticação acadêmica, demasiado politicamente correta, e os detentores do poder. Isso me leva a ter dúvidas sobre quem prevalecerá a médio prazo: o novo iluminismo libertador dos negros ou o caminho retomado das trevas em que adentramos. 
Quando, depois de longo questionamento judicial a sua nomeação, Sergio Camargo assumiu a presidência da Fundação Cultural Palmares, ninguém parecia saber o que faria ali um homem negro que repudia Zumbi, diz que o Brasil tem um "racismo Nutella" e afirma que a escravidão foi "benéfica para seus descendentes"11. No auge da movimentação pela morte de George Floyd, essa mesma autoridade chamava a consciência negra de "escória maldita" e a campanha Black Lives Matter, de "lixo esquerdopata". Hoje vejo em notícias diversas que a Fundação vem reescrevendo a experiência negra no Brasil, eliminando louvores a Zumbi e aos quilombos, expurgando abolicionistas como Luís Gama e André Rebouças, eliminando dos registros a escritora Carolina Maria de Jesus e nomes nacionais como o da vereadora assassinada Marielle Franco. A par disso, leio na internet que a Palmares agora certifica poucas reservas quilombolas, promove estudos sobre Chico Xavier e acolhe para diálogo pastores negros evangélicos.

A nomeação do presidente da Palmares insere-se na mesma sequência de escolhas para a destruição do Brasil moderno, num retrocesso contínuo, notado somente quando algum evento chocante atrai atenções da imprensa. O caso mais recente, ao se escreverem estas linhas, é a portaria, de 28/08/2020, do Ministério da Saúde, sobre procedimentos a serem seguidos por meninas e mulheres que necessitem de aborto legal, numa das três hipóteses previstas em nosso Código Penal. Ao exigir comunicação da intenção de abortar à polícia, juntamente com informações pormenorizadas sobre o estupro sofrido, e outras cobranças que tratam a vítima com suspeição criminal, a portaria é mais uma violação de direitos a incidir sobre pobres, dependentes dos serviços de saúde pública. Segue a mesma linha dos fanáticos que, poucos dias antes do procedimento prevista, foram para a porta do hospital em Recife para impedir o aborto da menina de dez anos, engravidada por tio de mais de trinta, estuprada desde que tinha seis anos. Adotada por um ministério sem titular, a nova portaria representa uma agressão fundamentalista a nosso Direito Positivo. Aparenta-se, nos objetivos, ao famigerado dossier sobre professores e agentes de segurança antifascistas, legitimado

\footnotetext{
${ }^{11}$ https://noticias.r7.com/brasil/presidente-da-fundacao-palmares-diz-que-escravidao-foi-benefica-27112019
} 
pelo pastor Ministro da Justiça contra "ameaça subversiva". Como se o antifascismo não fosse intrínseco à confissão democrática e o neofascismo a verdadeira ameaça!

O processo de regressão pela apropriação neopentecostal do poder político já conta com pastores na chefia dos Ministérios da Educação, da Justiça, da Mulher, Família e Direitos Humanos, tendo como outros agentes o chanceler, executor de diretrizes de um assessor presidencial evangélico, juntamente com o Ministro do Meio Ambiente, contrário ao desenvolvimento sustentável, aos direitos dos indígenas e ao controle da devastação da Amazônia. Representam o cerne da ideologia civil do Presidente da República, dedicado a acabar com a independência e à laicidade do Estado. Seu objetivo estratégico não-enunciado, mas deduzível: transformar o Brasil numa república pentecostal por ele dirigida. Ainda que, para isso, seja preciso atrair os militares, historicamente positivistas, distribuindo-os em postos-chaves civis, aumentando o orçamento de defesa em detrimento da educação e da saúde, floreando a propaganda do governo com desgastados slogans patrióticos. Dentro dessa mesma lógica, que desativou a SEPPIR e desvirtuou a Fundação Palmares, prepara até o Palácio do Planalto, retirando o quadro "Orixás" de Dejanira. Mais ominosamente, o chefe do Executivo fez questão de anunciar desde cedo a intenção de nomear um jurista evangélico para o Supremo Tribunal Federal, instituição laica do Estado multicultural, a qual, acima do credo não alardeado de cada um de seus membros veteranos, tem a função de defender a Constituição brasileira.

\section{O BOTE DA COBRA E O SAPO}

No dia 8 de agosto de 2020, a pandemia do coronavírus havia ultrapassado, no Brasil, as marcas de 3 milhões de casos registrados e 100 mil óbitos. Enquanto os contágios se espalhavam em áreas não específicas, as mortes predominavam em comunidades de gente pobre, majoritariamente negra. Se algo de útil a tragédia sanitária vinha tendo, era a demonstração cabal do descaso do Estado com a área social. Não somente na esfera da saúde, em que o SUS havia sido praticamente abandonado, mas também em matéria de habitação e saneamento, com incidência direta nas condições de prevenção do contágio. Viu-se, por exemplo, que mais de 35,7 \% da população brasileira, ou quase 100 milhões de pessoas, não contam com sistema de esgotos, e mais de 15 \%, ou 35 milhões 
de brasileiros, vivem sem abastecimento de água ${ }^{12}$. Ou seja, em outros termos, por mais que as cotas raciais e outras ações afirmativas tenham permitido a ascensão, sempre custosa, de uma parcela afrodescendente, o grosso da população "negra" vive em condições reminiscentes das senzalas.

Nesse quadro terrível se encaixa a religiosidade anti racionalista de facções cristãs dogmáticas e neopentecostais, da mesma maneira que emergem, na esfera planetária, o islamismo extremista, o hinduísmo nacionalista, o budismo intolerante e o judaísmo ortodoxo. É inegável que as versões protestantes do pentecostalismo são popularmente atraentes. Ademais de prometerem compensações celestiais para sofrimentos terrenos, prestam assistência a desvalidos e oferecem confiança aos aflitos, juntamente com milagres de cura e riqueza. Se isso resolverá os problemas da desigualdade social e racial no Brasil, tenho dúvidas. Depois que aprendi, em fala do babalorixá Rodney Williams ${ }^{13}$, sobre a existência de uma "capoeira gospel", pela qual brancos e negros crentes se apropriam dessa forma histórica de luta, e sobre o "acarajé de Jesus", adaptando alimento de orixás a religião monoteísta branca, não me surpreende que o candomblé, a umbanda e demais cultos congêneres continuem com poucos praticantes. É outro babalorixá, Sidnei Nogueira, quem explicita a forma pela qual, desde 1977, quando foi fundada, no Rio de Janeiro, a igreja pentecostal mais influente, "a perseguição às tradições de origem preta se agravou". E que as investidas evangélicas para conquistar o poder se acentuaram desde 1988, com a obtenção de concessões para estações de rádio e televisão. Em suas palavras: "O proselitismo religioso e eleitoral misturou-se de modo que não se sabe mais o que é religião e o que é política. Com isso, foi ao lixo (...) a suposta laicidade prevista em nossa Carta Magna".

As religiões geralmente dividem a humanidade entre o "nós" e os "outros", entre fiéis e infiéis. Por mais que viesse adaptando seus dogmas à evolução da ciência, a Igreja Católica precisou de um Concílio Ecumênico, nos anos 60 do século passado, para aceitar que todos os caminhos são válidos para chegar a Deus. Para o Islã, apesar de sua tolerância com os demais "seguidores do Livro" (o Velho Testamento dos judeus e

\footnotetext{
${ }^{12}$ https://inbec.com.br/blog/mais-35-milhoes-brasileiros-nao-possuem-abastecimento-agua-tratada-quase-100milhoes-nao-tem-acesso-coleta-esgoto

${ }^{13}$ https://www.youtube.com/watch?v=W248nnNIVFI
} 
cristãos), essa abertura abrangente é inconcebível. Para os evangélicos fundamentalistas, também. A eles se unem católicos integristas na corrente de irracionalidade que domina o cenário mundial. A solidariedade pregada se aplica somente aos correligionários. No caso do islã salafita, os que não se submetem aos ditames corânicos, são adversários a serem convertidos ou destruídos pela jihad - "guerra santa", não necessariamente violenta. No Brasil do governo atual, os "outros" são "comunistas", hereges, devassos, seguidores de seitas demoníacas, que precisam ser vencidos e, se possível, exterminados. É dos monoteísmos integristas que advêm a rejeição contemporânea à ciência, às vacinas, ao aborto em qualquer circunstância. Foram eles que, no sul dos Estados Unidos e na África do Sul do apartheid, forneceram base bíblica à discriminação legal contra os descendentes de Cam, neto amaldiçoado de Noé, condenado a vagar na África.

O que tem ocorrido de contrário aos direitos humanos e ao antirracismo no Brasil é tão chocante que me lembra a história do sapo hipnotizado pela cobra, petrificado de medo antes de ser devorado. O sapo, evidentemente, é o povo brasileiro não fanatizado. Só não digo que se trata de apatia congelante porque os promotores e promotoras da consciência negra se acham muito ativos. Entre eles incluo jornalistas militantes, humoristas simpatizantes, cantores e compositores de rap voltados para o tema, artistas e escritoras, além de professores e pesquisadores variados. O que falta é ação política capaz de mudar o cenário. Isso requer união. Como assinala Silvio Almeida, de nada adianta uma pessoa dizer-se sem preconceitos, pró igualdade racial, e ser favorável às "medidas de austeridade", que incidirão sempre mais sobre os "negros". Tanto ele como Djamila Ribeiro são ativistas admiráveis que, com foco nas identidades assumidas, vêm atuando com mensagens de alcance abrangente.

Na presente fase doentia de nossa pátria dividida, em que as polarizações atingem um nível de agressividade insano, é essencial que negros e brancos antirracistas tenham consciência clara de quem são os adversários principais. Lideranças com foco particularizado têm, evidentemente, todo o direito de dar continuidade a seu trabalho. Sem abandonarem os ensinamentos sobre o racismo estrutural, tenho esperança de que elas e eles saberão unir-se aos potenciais aliados, cientes do lugar de fala respectivo, para enfrentar a ameaça comum. Isso poderia, talvez, abrir o melhor caminho para a assunção 
real pela sociedade brasileira daquilo que ela factualmente é: um conjunto díspar, heteróclito, cuja maioria é preta e parda, de formação cultural sincrética. Se a predominância de uma ideologia fundamentalista e polarizadora, imposta por um governo branqueado, continuar a fazer estragos naquilo que se havia conseguido para o aprimoramento das relações nacionais de "raça", sexo e gênero, de nada adiantará a bagagem identitária aguçada de alguns setores específicos.

Brasília, agosto de 2020. 


\section{REFERÊNCIAS BIBLIOGRÁFICAS}

Agamben, G. (2004). Estado de Exceção. São Paulo: Boitempo.

Almeida, S. (2019). Racismo Estrutural. São Paulo, Sueli Carneiro: Pólen.

Florestan, F. (2017). O negro no mundo dos brancos. São Paulo: Global Editora, 2a Ed., 3aㅗ Reimpressão.

Freyre, G. (1988). Casa Grande \& Senzala. Rio de Janeiro: José Olympio, 21a Ed.

Lind, M. (1996). The Next American Nation. Nova York: Free Press, p. 14 e 215-216.

Lindgren-Alves, J. A. (2018). 'A Década das Conferências (1990-1999)', Posfácio à 2ạ Edição. Brasília: FUNAG, p. 512-514.

. (2005). Os Direitos Humanos na Pós-Modernidade. São Paulo: Perspectiva, p. $115-121$

Marx, A. (1998). Making Race and Nation. Cambridge: Cambridge University Press, p. 273 Mbembe, A. (2018). Necropolítica. São Paulo: N-1 Edições.

Nogueira, S. (2020). Intolerância Religiosa. São Paulo, Sueli Carneiro: Editora Jandaíra, p. 25.

Ribeiro, D. (2019). Lugar de fala. São Paulo, Sueli Carneiro: Pólen.

Roland, E. (2004). Depoimento. Rio de Janeiro: CPDOC/FGV, p. 83-84.

Traverso, E. (2018). Melancolia de Esquerda: Marxismo, História e Memória. Belo Horizonte: Editora Ayiné, p. 368.

. (2018). Melancolia de Esquerda: Marxismo, História e Memória. Belo Horizonte: Editora Ayiné, pp. 367-369. 
